\title{
PHÂN TÍCH CHÍNH SÁCH XÃ HộI DỰA TRÊN KHUNG ĐÁNH GIÁ QUẢN TR!̣ BỀN VŨ̉NG
}

\author{
Bùi Thế Cường ${ }^{(1)}$ \\ (1) Viện Hàn lâm Khoa học Xã hội Việt Nam \\ Ngày nhận bài 17/12/2019; Ngày gửi phản biện 20/12/2019; Chấp nhận đăng 24/01/2020 \\ Liên hẹe email: cuongbuithe@yahoo.com \\ https://doi.org/10.37550/tdmu.VJS/2020.01.008
}

\section{Tóm tắt}

Tù hơn mười năm qua, Quỹ Bertelsmann thục hiện dụ án đánh giá quản trị bền vĩng cho các nước thuộc khối EU và OECD mang tên "Chỉ báo quản trị bền vĩng" (SGI). Dự án dựa trên một khung đánh giá quản trị bền vũng có chất lương cao về lý thuyết và đo luò̀ng thực nghiệm. Bài viết này giới thiệu khung lý thuyết của SGI, tập trung vào hợp phần chính sách xã hội, kết quả đánh giá thành quả chính sách xã họi năm 2018 do dụ án thực hiện và gợi ý khả năng ứng dụng khung lý thuyết SGI vào phân tích chính sách xã hội và hành chính công ở Việt Nam.

Tù khóa: chính sách xã họi, quản trị bền vĩng

\section{Abstract}

\section{SOCIAL POLICY ANALYSIS BASED ON SUSTAINABLE GOVERNANCE INDICATORS}

Over the past ten years, the Bertelsmann Foundation has carried out a project on sustainable governance assessment for the EU and OECD countries called "Sustainable Governance Indicators" (SGI). The project is based on a theoretically and empirically high-quality framework of sustainable governance assessment. The article introduces SGI's theoretical framework, focusing on the pillar of social policy performance and the key findings in social policy performance implemented by the project in 2018. On the basis of SGI, the article suggests the prospects of applying the SGI to social policy analysis and public administration in Vietnam.

\section{1. Đặt vấn đề}

Loài người đang phải đương đầu với nhiều thách thức nghiêm trọng. Nhưng đa số quốc gia trên thế giới đều đang thất bại trong việc có được một nền quản trị bền vững. Nhận thức tình trạng ấy, Quỹ Bertelsmann (Cộng hòa liên bang Đức) đã tài trợ một dự án mang tên "Chỉ báo quản trị bền vững” (Sustainable Governance Indicators, SGI) để phân tích nền quản trị trong các quốc gia thuộc EU [European Union] và OECD [Organisation for Economic Cooperation and Development]. Dự án SGI đã phát triển 
một khung phân tích quản trị về mặt khái niệm và chỉ số đo lường thực nghiệm (Schraad-Tischler and Seelkopf, 2015). Dựa trên khung đánh giá chung, các nước thành viên xây dựng báo cáo quốc gia hàng năm. Báo cáo sớm nhất của dự án SGI ra mắt năm 2009, xem xét tình trạng quản trị bền vững của các nước thành viên dự án trong giai đoạn 2005-2007. Sau đó lần lượt xuất hiện các báo cáo SGI năm 2011, 2014, 2015, 2016, 2017, 2018 và 2019. Hiện có 41 nước tham gia dự án (SGI Sustainable Governance Indicators and Bertelsmann Stiftung, 2019a).

Bài viết trình bày khung đánh giá quản trị bền vững SGI, tập trung vào hợp phần chính sách xã hội và đề cập kết quả đánh giá thành tựu chính sách xã hội 2018 do dự án thực hiện. Bài viết có năm phần. Sau phần mở đầu, phần hai mô tả khung đánh giá quản trị bền vững chung; phần ba mô tả hợp phần đánh giá chính sách xã hội bền vững trong khung SGI; phần bốn giới thiệu kết quả đánh giá chính sách xã hội năm 2018 của các nước thành viên EU và $\mathrm{OECD}$; phần cuối đề cập khả năng áp dụng mô hình SGI trong đào tạo và phân tích chính sách xã hội ở Việt Nam. Đây là sản phẩm của "Chương trình Nghiên cứu khoa học các vấn đề xã hội” do Viện Phát triển Chiến lược Trường Đại học Thủ Dầu Một thực hiện theo Quyết định số 1355/QĐ-ĐHTDM (3/9/2019).

\section{Khung đánh giá quản trị bền vũng}

SGI được thiết kế với một cấu trúc súc tích và chặt chẽ, đi từ khái niệm, lý thuyết, đến các chỉ số đo thực nghiệm. Hơn bao giờ hết, ngày nay loài người cần tồn tại dựa trên nguyên tắc phát triển bền vững, trong lĩnh vực kinh tế, môi trường và xã hội. Để phát triển bền vững, các quốc gia phải có nền quản trị bền vững. Tương thích với khái niệm phát triển bền vững, khung phân tích và đánh giá SGI thiết kế nên khái niệm quản trị bền vững bao gồm ba trụ cột là: Thành quả chính sách [Policy Performance], Nền dân chủ [Democracy], và Quản trị [Governance]. Hình 1 thể hiện tổng quan khung chỉ báo quản trị bền vững (Schraad-Tischler and Seelkopf, 2015: 3).

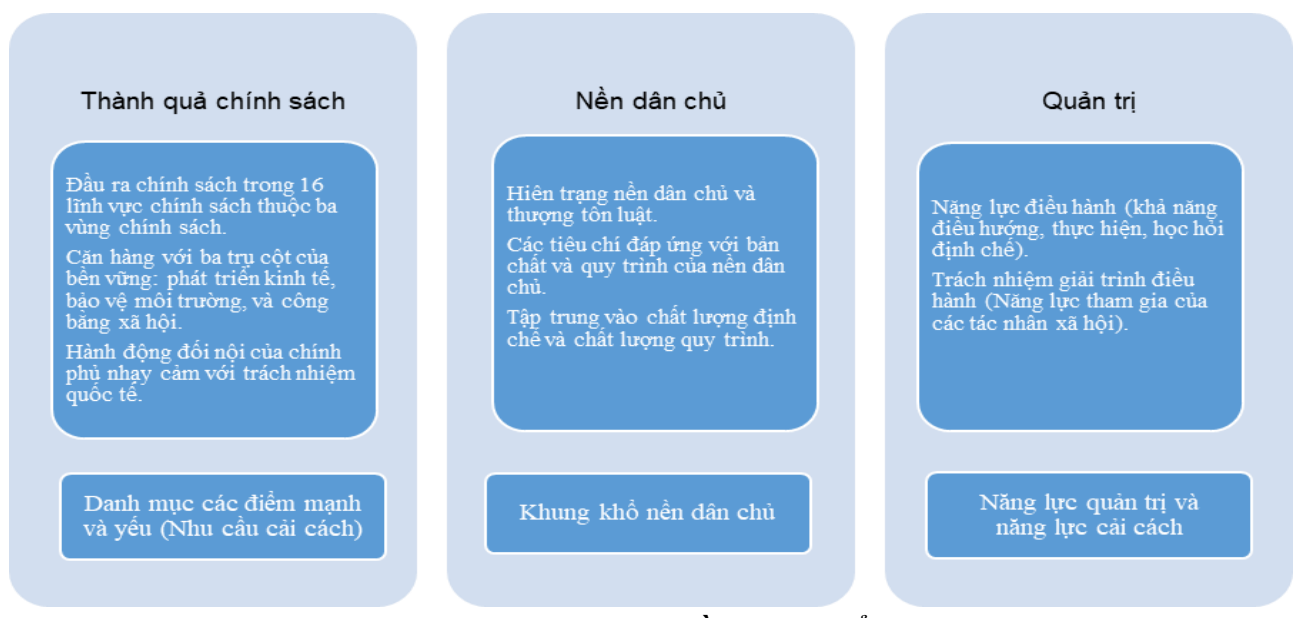

Hình 1. Khung chỉ báo quản trị bền vũng tổng quát, ba trụ cột

Nguồn: Schraad-Tischler and Seelkopf, 2015: 3. 
Trụ cột một: thành quả chính sách, là kết quả tổng hợp từ 16 lĩnh vực chính sách thuộc ba khu vực chính sách, đáp ứng với ba lĩnh vực chủ chốt của phát triển bền vững (phát triển kinh tế, bảo vệ môi trường, và công bằng xã hội). Ngoài ra, chính phủ còn phải có chính sách đáp ứng trách nhiệm quốc tế cho cả ba lĩnh vực đó. Kết quả đánh giá các thành quả chính sách sẽ phác họa nên bức tranh về những điểm mạnh và điểm yếu trong chính sách của chính phủ, tạo ra căn cứ khoa học để cải thiện chính sách.

Trụ cột hai: nền dân chủ, phân tích và đánh giá hiện trạng nền dân chủ và tình trạng thượng tôn pháp luật. Nó bao gồm các chỉ số phản ánh bản chất và quy trình dân chủ, chú trọng vào đánh giá chất lượng định chế và quy trình. Kết quả đánh giá trụ cột hai làm rõ nền tảng khung khổ của nền dân chủ cho quản trị bền vững.

Trụ cột ba: quản trị, gồm hai nội dung. Một là năng lực điều hành, xem xét khả năng điều hướng [steering capability], thực hiện, và khả năng các định chế có thể tự học hỏi. Hai là trách nhiệm giải trình của điều hành, thể hiện năng lực của các tác nhân xã hội tham gia quản trị. Kết quả đánh giá trụ cột ba làm rõ năng lực quản trị và năng lực cải thiện quản trị.

SGI kết hợp đánh giá định tính của chuyên gia và dữ liệu định lượng từ các nguồn thống kê chính thức để có được các chỉ báo định tính và định lượng cụ thể. SGI 2019 (mới nhất) bao gồm 71 chỉ báo định tính và 74 chỉ báo định lượng cụ thể. Các chỉ báo này được cho điểm trên thang 10 điểm. Các thang điểm được mô tả rõ ràng để chuẩn hóa giữa các nước và theo thời gian. Thông qua chuỗi thuật toán, các chỉ báo cụ thể kết hợp với nhau qua bốn bước để tạo nên đánh giá cuối cùng về quản trị bền vững của một quốc gia. Bước một, các chỉ báo cụ thể kết hợp thành các chỉ số tổng hợp cấp 1 cho các lĩnh vực. Bước hai, những chỉ số tổng hợp lĩnh vực cấp 1 kết hợp với nhau để tạo nên các chỉ số tổng hợp cấp 2 cho các khu vực. Bước ba, các chỉ số tổng hợp cấp 2 cho các khu vực kết hợp với nhau tạo nên ba chỉ số [index] trụ cột: Thành quả chính sách [Policy Performance Index], Nền dân chủ [Democracy Index], và Quản trị [Governance Index]. Bước bốn, ba chỉ số trụ cột kết hợp để cuối cùng hình thành một chỉ số tổng hợp trên thang điểm 10 phản ánh trình độ quản trị bền vững ở một quốc gia. Sau khi có điểm tổng hợp, 41 nước trong mẫu khảo sát được xếp hạng (Schraad-Tischler and Seelkopf, 2015; SGI Sustainable Governance Indicators and Bertelsmann Stiftung, 2019a, 2019b).

\section{Khung đánh giá chính sách xã hội}

Mục tiêu bài này tập trung vào khu vực các chính sách xã hội trong dự án SGI. Trong khung phân tích SGI tổng quát (Bảng 1), trụ cột "Thành quả chính sách" gồm ba khu vực: Các chính sách kinh tế (có sáu lĩnh vực chính sách), Các chính sách xã hội (tám lĩnh vực chính sách), và Các chính sách môi trường (hai lĩnh vực chính sách). Tám lĩnh vực chính sách trong khu vực các chính sách xã hội là: giáo dục, bao gồm xã hội [social inclusion], sức khỏe, gia đình, hệ thống hưu trí, hội nhập [integration], an toàn [safe living], và bất bình đẳng toàn cầu (Bảng 1 ). 
Bảng 1. Cấu thành của tru cột "thành quả chính sách" trong mô hình SGI

\begin{tabular}{|c|c|l|}
\hline & Ba khu vực chính sách & \multicolumn{1}{c|}{16 lĩnh vực chính sách } \\
\hline \multirow{2}{*}{$\begin{array}{c}\text { Trụ cột } \\
\text { "Thành } \\
\text { quả chính } \\
\text { sách" }\end{array}$} & Các chính sách kinh tế & $\begin{array}{l}\text { Kinh tế, Các thị trường lao động, Thuế, Ngân sách, Nghiên } \\
\text { cứu, đổi mới và cơ sở hạ tầng, Hệ thông tài chính toàn cầu. }\end{array}$ \\
\cline { 2 - 3 } & Các chính sách xã hội & $\begin{array}{l}\text { Giáo dục, Bao gồm xã hội, Sức khỏe, Gia đình, Hưu trí, } \\
\text { Hội nhập, An ninh, Bất bình đẳng toàn cầu. }\end{array}$ \\
\cline { 2 - 3 } & Cánh sách môi trường & Môi trường, Bảo vệ môi trường toàn cầu. \\
\hline
\end{tabular}

Nguồn: SGI Sustainable Governance Indicators and Bertelsmann Stiftung,

https://www.sgi-network.org/2019/Mission_Statement

\subsection{Cấu trúc chung}

Cấu trúc chung của khu vực các chính sách xã hội có hai phần, một câu hỏi chính để chuyên gia phân tích định tính và một tập các lĩnh vực chính sách thành phần. Câu hỏi chính để đánh giá tổng quát chính sách xã hội là: "Các chính sách xã hội có thúc đẩy cho một xã hội bình đẳng và công bằng [fair] không?”. Tập các lĩnh vực thành phần của khu vực các chính sách xã hội bao gồm tám lĩnh vực chính sách nêu trên. Mỗi lĩnh vực thành phần này đóng góp bằng nhau vào điểm đánh giá chính sách xã hội tổng quát: Mỗi lĩnh vực chiếm 12,5\% trọng lượng vào điểm đánh giá chung (12,5\% x $8=100,0 \%)$.

Tiếp đến, trong mỗi lĩnh vực thành phần lại có một cấu trúc gồm hai bộ phận: một câu hỏi đánh giá khái quát về chính sách của lĩnh vực đó và một tập các chỉ báo định lượng cụ thể. Bộ phận đánh giá chính sách định tính chiếm trọng lượng 50\%, bộ phận tập hợp các chỉ báo chiếm trọng lượng 50\% còn lại. Trong bộ phận hai, mỗi chỉ báo đều có một trọng lượng ngang nhau, sao cho cộng lại bằng $50 \%$. Dựa trên bảng điểm đã cho, nhóm chuyên gia phân tích và gán cho mỗi chỉ báo một giá trị trong thang 10 điểm. Thông qua thuật toán đã xác định, các chỉ báo trong một lĩnh vực chính sách xã hội được kết hợp để tạo nên chỉ số tổng hợp của lĩnh vực chính sách xã hội đó. Tiếp theo, các chỉ số tổng hợp của các lĩnh vực chính sách xã hội được kết hợp theo thuật toán để tạo ra chỉ số tổng hợp của khu vực chính sách xã hội ở một quốc gia. Trước hết, chỉ số này cung cấp một căn cứ định lượng để đánh giá hiện trạng chính sách xã hội của một quốc gia tại một thời điểm nhất định. Ta cũng có thể dùng để so sánh sự phát triển của chính sách xã hội quốc gia đó qua thời gian, hoặc so sánh với chính sách xã hội quốc gia khác.

\subsection{Tám lĩnh vục thành phần của chính sách xã hội}

Phần này trình bày mục tiêu đánh giá định tính (trình bày dưới dạng câu hỏi dành cho chuyên gia cho điểm dựa trên đánh giá định tính) và tập các chỉ báo đánh giá định lượng (dựa trên các nguồn thống kê chính thức) trong tám lĩnh vực thành phần của khu vực chính sách xã hội.

Giáo dục: Câu hỏi chính: "Chính sách giáo dục có cung cấp giáo dục và đào tạo chất lượng cao [high-quality] và công bằng [equitable] không?”. Hai cấu thành chính là 
“Chính sách giáo dục” chiếm trọng lượng 50\% trong đánh giá, và năm chỉ báo định lượng chiếm trọng lượng 50\% trong đánh giá. Năm chỉ báo đó là: Tỷ lệ nhập học trung học phổ thông [upper secondary attainment], tỷ lệ vào đại học [tertiary attainment], kết quả PISA, PISA và xuất thân kinh tế-xã hội, chi phí trước khi vào tiểu học [pre-primary expenditure]. Vì có năm chỉ báo nên mỗi chỉ báo đóng góp ngang nhau mức $10 \%$ trọng lượng $(10 \%$ x $5=50 \%)$.

Bao gồm xã hội: Câu hỏi chính: "Các chính sách phúc lợi có hỗ trợ bình đẳng cơ hội trong xã hội và phòng ngừa nghèo không?". Hai cấu thành chính là "Chính sách bao gồm xã hội” (50\%) và sáu chỉ báo định lượng (50\%). Sáu chỉ báo là: Tỷ lệ nghèo, tỷ lệ $\mathrm{NEET}^{(1)}$, chỉ số GINI, bình đẳng giới trong cơ quan lập pháp, hài lòng với cuộc sống [life satisfaction], và tỷ số Palma ${ }^{(2)}$. Vì có sáu chỉ báo nên mỗi chỉ báo đóng góp $7,14 \%$ trọng lượng $(7,14 \%$ x $6=50,0 \%)$.

Sức khỏe: Câu hỏi chính của lĩnh vực thành phần sức khỏe: "Các chính sách có cung cấp chăm sóc sức khỏe chất lượng cao, có tính bao trùm [inclusive] và hiệu quả về chi phí [cost-efficient] không?". Hai cấu thành chính là "Chính sách sức khỏe” $(50 \%)$ và bốn chỉ báo định lượng $(50 \%)$. Bốn chỉ báo đó là: Chi tiêu chính phủ cho các chương trình y tế dự phòng [preventive health programs], tuổi thọ kỳ vọng [life expectancy], tỷ suất chết trẻ sơ sinh [infant mortality], và cảm nhận tình trạng sức khỏe [perceived health status]. Vì có bốn chỉ báo nên mỗi chỉ báo đóng góp 12,5\% trọng lượng (12,5\% x 4 = 50,0\%).

Gia đình: Câu hỏi chính của lĩnh vực thành phần này là "Các chính sách gia đình có tối đa hóa các cơ hội cho cả cha lẫn mẹ không? Có tồn tại một hệ thống vững chắc hỗ trợ gia đình và phục vụ chăm sóc trẻ em không?”. Hai cấu thành chính là "Chính sách gia đình" (50\%) và năm chỉ báo định lượng $(50 \%)$. Năm chỉ báo đó là: Mật độ chăm sóc trẻ em [child care density] độ tuổi 0-2, mật độ chăm sóc trẻ em độ tuổi 3-5, tỷ lệ sinh [fertility rate], tỷ lệ nghèo trẻ em [child poverty rate], và tỷ lệ phụ nữ tham gia lực lượng lao động [female labor force participation rate]. Vì có năm chỉ báo nên mỗi chỉ báo đóng góp $10 \%$ trọng lượng $(10 \%$ x $5=50,0 \%)$.

Các hệ thống hưu trí: Câu hỏi chính của lĩnh vực thành phần này là "Các hệ thống hưu trí có được thiết kế để đạt được sự bền vững tài chính không? Các chính sách hưu trí có nhằm mục tiêu công bằng liên thế hệ [intergenerational equity] không?". Hai cấu thành chính là "Chính sách hưu trí" $(50 \%)$ và ba chỉ báo định lượng $(50 \%)$. Ba chỉ báo đó là: việc làm người cao tuổi [older employment], tỷ suất phụ thuộc người cao tuổi [old age dependency ratio], và người cao tuổi nghèo [senior citizen poverty]. Vì có ba chỉ báo nên mỗi chỉ báo đóng góp 16,67\% trọng lượng $(16,67 \%$ x $3=50,1 \%)$.

Hội nhập [integration]: Trên thực tế, đây là cấu phần mô tả tình trạng hội nhập của dân nhập cư hoặc tộc người thiểu số. Câu hỏi chính của lĩnh vực thành phần này là “Các chính sách văn hóa, giáo dục, và xã hội có hỗ trợ tích cực cho các cộng đồng nhập cư hội nhập không?”. Hai cấu thành chính là "Chính sách hội nhập" $(50 \%)$ và bốn chỉ báo định lượng $(50 \%)$. Bốn chỉ báo đó là: Tỷ lệ nhập học trung học phổ thông 
FB-N [FB-N upper secondary attainment], tỷ lệ vào đại học FB-N [FB-N tertiary attainment], mức thất nghiệp FB-N [FB-N unemployment], và mức có việc làm $\mathrm{FB}-\mathrm{N}$ [FB-N employment]. Vì có bốn chỉ báo nên mỗi chỉ báo đóng góp 12,5\% trọng lượng $(12,5 \% \text { × } 4=50 \%)^{(3)}$.

An toàn [safe living]: Câu hỏi chính của lĩnh vực thành phần này là 'Chính sách trật tự trị an [internal security] có bảo vệ công dân trước tội phạm không? Người dân có tin tưởng lực lượng công an không?”. Hai cấu thành chính là “Chính sách trật tự xã hội” (50\%) và ba chỉ báo định lượng (50\%). Ba chỉ báo đó là: tội phạm giết người [homicide], an toàn cá nhân [personal security], và tin cậy cảnh sát [confidence in police]. Vì có ba chỉ báo nên mỗi chỉ báo đóng góp 16,67\% trọng lượng $(16,67 \%$ x $3=50,1 \%)$.

Bất bình đẩng toàn cầu: Câu hỏi chính của lĩnh vực thành phần này là "Chính phủ có đấu tranh giải quyết bất bình đẳng toàn cầu không? Chính phủ có tích cực tham gia các khung khổ toàn cầu [global frameworks] không?”. Hai cấu thành chính là "Chính sách xã hội toàn cầu" (50\%) và một chỉ báo định lượng duy nhất đo mức ODA của quốc gia đó đóng góp cho thế giới $(50 \%)$.

\section{Kết quả đánh giá chính sách xã hội quốc gia 2018}

Do khuôn khổ tạp chí hạn chế, trong bài viết này, tác giả chỉ đề cập kết quả đánh giá tổng quát khu vực các chính sách xã hội năm 2018 được xuất bản trong báo cáo SGI 2019, và bỏ qua việc đánh giá trong từng lĩnh vực thành phần của chính sách xã hội.

\subsection{Chỉ số và thứ hạng chính sách xã hội quốc gia}

Bảng 2 trình bày sự phân bố của các nước vào khung đánh giá chính sách xã hội theo điểm (từ 0 đến 10 ) và thứ hạng. Các nước lại được nhóm vào bốn khối nước theo thang điểm, bao gồm nhóm dẫn đầu [Top] (điểm 9 và 10), nhóm trung bình trên [Upper middle] (điểm 6,7 , và 8 ), nhóm trung bình dưới [Lower middle] (điểm 3,4 , và 5 ), và nhóm đáy [Bottom] (điểm 1 và 2 ).

Bảng 2. Điểm số và thứ hạng chính sách xã hội của 41 nước theo nhóm và điểm, 2018

\begin{tabular}{|c|c|c|c|c|}
\hline TT & Nhóm & Điểm & Số nước & Nước: Điểm số/ Vị trí bậc \\
\hline \multirow{2}{*}{1} & \multirow{2}{*}{ Dẫn đầu } & 10 & & \\
\hline & & 9 & & \\
\hline \multirow{3}{*}{2} & \multirow{3}{*}{$\begin{array}{l}\text { Trung } \\
\text { bình trên }\end{array}$} & 8 & 1 & Na Uy $8,0 / 1$. \\
\hline & & 7 & 9 & $\begin{array}{l}\text { Denmark 7,8/2; Luxemburg 7,5/3; Thụy Điển 7,4/4; Phần Lan } \\
\text { 7,3/5; Canada 7,2/6; New Zealand 7,2/6; CHLB Đức 7,1/8; } \\
\text { Vương quốc Anh 7,1/8; Iceland 7,1/8. }\end{array}$ \\
\hline & & 6 & 14 & $\begin{array}{l}\text { Thụy Sĩ 6,9/11; Pháp 6,8/12; Estonia 6,8/12; Hà Land 6,7/14; } \\
\text { Australia 6,5/15; Ireland 6,5/15; Slovenia 6,5/15; Tây Ban } \\
\text { Nha 6,5/15; Bỉ 6,4/19; Áo 6,3/20; Czechia 6,2/21; Hàn Quốc } \\
\text { 6,1/22; Nhật Bản 6,0/23; Lithuania 6,0/23. }\end{array}$ \\
\hline
\end{tabular}




\begin{tabular}{|c|l|c|c|l|}
\hline & & 5 & 11 & $\begin{array}{l}\text { Israel 5,9/25; Bồ Đào Nha 5,9/25; Cyprus 5,7/27; Italy 5,5/28; } \\
\text { Hoa Kỳ 5,4/29; Malta 5,4/29; Ba Lan 5,3/31; Latvia 5,2/32; } \\
\text { Chile 5,1/33; Thổ Nhĩ Kỳ 5,1/33; Slovakia 5,0/35. }\end{array}$ \\
\cline { 3 - 6 } 3 & \multirow{2}{*}{$\begin{array}{l}\text { Trung } \\
\text { bình dưới }\end{array}$} & 4 & 6 & $\begin{array}{l}\text { Croatia 4,9/36; Hy Lạp 4,8/37; Hungary 4,6/38; Romania } \\
\text { 4,5/39; Bulgaria 4,3/40; Mexico 4,0/41. }\end{array}$ \\
\cline { 3 - 6 } & \multirow{2}{*}{ Đáy } & 3 & & \\
\cline { 3 - 6 } & 1 & & & \\
\hline
\end{tabular}

Nguồn: SGI Sustainable Governance Indicators and Bertelsmann Stiftung, 2019a, https://www.sgi-network.org/2019/Policy_Performance/Social_Policies.

Không nước nào rơi vào nhóm dẫn đầu hay nhóm đáy, tất cả các nước trong mẫu nghiên cứu đều tập trung ở nhóm trung bình trên (24 nước, chiếm 66\% mẫu nghiên cứu) và nhóm trung bình dưới (17 nước, $34 \%)$. Điều này dễ hiểu vì mẫu khảo sát là các nước thành viên $\mathrm{OECD}$ hay $\mathrm{EU}$. Tuy nhiên, trong khi không nước nào rơi vào nhóm đáy, thậm chí bị điểm 3, song chỉ $\mathrm{Na}$ Uy là nước duy nhất đạt điểm 8,0 . Như ta thấy, điểm 9 và 10 quá hoàn hảo để một nước có thể lên tới thang điểm này (SGI Sustainable Governance Indicators and Bertelsmann Stiftung, 2019b).

\subsection{Ba quốc gia điển hình}

Ta xem xét một số nước điển hình. Trước hết $\mathrm{Na} U y$, nước dẫn đầu. Khu vực chính sách xã hội của $\mathrm{Na} U y$ đạt điểm 8,0 . Trong đó, các điểm lĩnh vực thành phần: giáo dục $(7,2)$, bao gồm xã hội $(8,2)$, sức khỏe $(7,1)$, gia đình $(8,2)$, hưu trí $(8,1)$, hội nhập $(7,5)$, an toàn $(8,5)$ và bất bình đẳng toàn cầu $(9,0)$.

Đánh giá chung cho thấy quốc gia này có mạng an toàn xã hội [social safety net] rộng rãi. Mức đi học [educational attainment] rất cao, tuy một số lĩnh vực điểm PISA thấp. Hệ thống bảo hiểm xã hội bao trùm và hào phóng khiến tỷ lệ nghèo rất thấp. Hệ thống chăm sóc sức khỏe phổ quát có chất lượng cao. Nhưng gần đây người dân phản đối một số cải cách nhằm hỗ trợ bệnh viện nhỏ và thúc đẩy hiệu quả chi phí điều trị. Trợ cấp gia đình hào phóng và các chương trình bình đẳng giới góp phần đảm bảo tỷ lệ nữ đi làm cao và mức sinh cao. Từ nhiều thập niên, mức sinh cao là hiện tượng hiếm trong hầu hết các nước châu Âu và Nhật. Nguồn thu nhập dư dả đảm bảo tính bền vững cho hệ thống y tế và hưu trí. Na Uy áp dụng một số giải pháp khích lệ mới khiến nâng cao được mức tuổi về hưu thực tế. Mặc dù chú trọng đầu tư cho hội nhập di dân, nhưng kết quả không khả quan. Người nhập cư không phải gốc Tây phương bị phân biệt đối xử trong thị trường lao động và nhà ở. Tuy nhập cư ngày càng trở thành tranh luận nóng trong bầu cử, song đa số cử tri không ủng hộ các đảng chính trị cánh hữu và chống nhập cư. Mức tội phạm rất thấp (Sverdrup et al., 2019).

Tương phản, Bulgaria là nước gần đội sổ (40/41). Khu vực chính sách xã hội đạt điểm 4,3. Trong đó các điểm lĩnh vực thành phần: giáo dục $(4,7)$, bao gồm xã hội $(3,7)$, sức khỏe $(4,3)$, gia đình $(5,4)$, hưu trí $(4,6)$, hội nhập $(4,5)$, an toàn $(4,6)$, và bất bình 
đẳng toàn cầu $(2,6)$. Thực trạng 2019 gần như không thay đổi so với năm năm trước (2014). Đánh giá định tính chuyên gia cho thấy chất lượng giáo dục tương đối thấp và khác biệt rõ theo vùng địa lý. Tỷ lệ chi ngân sách cho phổ thông trong GDP tăng. Bất bình đẳng thu nhập ở mức cao và xu hướng tăng. Tồn tại nhiều vấn đề trong hội nhập của các tộc thiểu số, nhập cư và người học vấn thấp. Hệ thống chăm sóc sức khỏe có tính bao trùm và có những chỉ số đầu ra được cải thiện trong những năm gần đây. Tăng trưởng kinh tế góp phần ổn định tài chính cho y tế nhưng người dân phổ biến có "phong bao" cho nhân viên y tế để được chăm sóc nhanh và tốt hơn. Dịch vụ công chăm sóc trẻ em hạn chế nhưng mạng hỗ trợ gia đình khá mạnh và cha mẹ được giảm giờ làm để chăm sóc con. Chế độ hưu trí không có tác động mạnh trong việc giảm nghèo ở người già. Tài chính của hệ thống cũng không bền vững. Chưa có chính sách hội nhập cho dân nhập cư. Tiếng nói chống dân nhập cư trong chính trường khá mạnh. Tội phạm có tổ chức và bạo lực đối với dân nhập cư ở mức nghiêm trọng (Ganev et al., 2019).

Chúng ta vừa điểm qua nước dẫn đầu và nước sát đội sổ với số điểm 8,0 và 4,3 . Giờ ta nhìn vào Hàn Quốc, nước có thứ hạng ở khoảng giữa (22/41 nước). Khu vực chính sách xã hội của Hàn Quốc đạt điểm 6,1. Trong đó, các điểm lĩnh vực thành phần: giáo dục $(7,5)$, bao gồm xã hội $(4,9)$, sức khỏe $(7,3)$, gia đình $(5,4)$, hưu trí $(5,4)$, hội nhập $(6,2)$, an toàn $(7,8)$, và bất bình đẳng toàn cầu $(4,3)$. Đánh giá định tính chuyên gia cho thấy đầu ra giáo dục tốt, mức nhập đại học cao. Nhưng khác với các nước Âu-Mỹ, tuy đã nhiều nỗ lực thay đổi, song chương trình quá tải và học gạo vẫn nặng nề. Hệ thống chăm sóc sức khỏe có tính phổ quát và chất lượng cao nhưng tổng chi ngân sách cho y tế tương đối thấp. Người dân phải cùng chi trả y tế cao nhưng Hàn Quốc đang nỗ lực hỗ trợ cho các gia đình phải trả chi phí y tế cao. Bất bình đẳng gia tăng và nghèo tương đối là nghiêm trọng. Trợ cấp thu nhập [transfer payments] để phòng nghèo còn hạn chế. Ít có khuyến khích giúp phụ nữ tham gia lực lượng lao động. Các chính sách hỗ trợ phụ nữ kết hợp giữa việc làm và gia đình chưa có hiệu quả. Người cao tuổi nghèo là vấn đề lo ngại. Chính phủ đang phát triển quỹ hưu cơ bản [basic pension] cho người già thu nhập thấp. Chính phủ đang xúc tiến cải cách hưu trí mở rộng độ phổ quát. Nhập cư là chủ đề tranh luận nóng. Công luận phản ứng mạnh với chính sách cấp quy chế tị nạn cho người từ vùng xung đột chiến tranh (Kalinowski et al., 2019).

Nhờ khung đánh giá chính sách xã hội chung, các nước có thể nhìn vào thực trạng của nhau, để học hỏi, thi đua, và thay đổi bản thân.

\section{Hàm ý cho phân tích chính sách xã hội và quản trị công ở Việt Nam}

Hiện nay, mọi quốc gia đều đứng trước những thách thức to lớn, phức tạp và đầy tính đe dọa, đòi hỏi cộng đồng làm chính sách mỗi nước phải thích ứng nhanh và học hỏi nhau tích cực. SGI là một công cụ giám sát [monitoring instrument], qua thực tiễn hoạt động hơn mười năm đã chứng tỏ tính hữu hiệu nhất định. SGI có thể là một mô hình lý thuyết gợi ý tốt cho nghiên cứu thực nghiệm trong nhiều lĩnh vực như khoa học 
chính sách công, hành chính công, xã hội học, chính sách xã hội, chính trị học, kinh tế học, nghiên cứu môi trường. Nó cũng có thể là khung nghiên cứu có khả năng gợi mở tốt cho việc đánh giá cả ở cấp độ quốc gia lẫn địa phương (tỉnh, huyện) và thậm chí cấp cơ sở. SGI cũng là tài liệu tham khảo bổ ích trong giảng dạy các bộ môn kể trên. Tuy được thiết kế và thực hiện cho khối các nước phát triển, song người ta có thể áp dụng được vào bối cảnh các nước đang phát triển, và xa hơn có thể áp dụng từng phần nhỏ của mô hình cho những dạng công trình nghiên cứu khác nhau.

Mục tiêu thực tiễn của bài viết là mô tả khung phân tích hợp phần chính sách xã hội trong khung SGI, giới thiệu một nguồn tài liệu tham khảo cho nghiên cứu, thực hành, và đào tạo chính sách xã hội. Hy vọng bài viết khích lệ một số học viên cao học và nghiên cứu sinh trong ngành chính sách công, xã hội học, công tác xã hội, cũng như trong nhiều bộ môn khác, thử áp dụng SGI trong luận văn, luận án của mình. Thực hiện công trình sau đại học, bạn không cần làm một đánh giá cho toàn bộ lĩnh vực chính sách xã hội, điều khó khả thi. Bạn có thể chọn chỉ một trong tám lĩnh vực thành phần kể trên. Khi đó khung phân tích nói trên sẽ là chỉ dẫn tốt để hình thành khung lý thuyết cho công trình của mình. Phần nghiên cứu mới [original research] của bạn là thu thập dữ liệu (định lượng và định tính) để lấp đầy khung phân tích ấy, đem lại những kết quả mang tính chỉ báo về một lĩnh vực nào đó trong chính sách xã hội ở Việt Nam.

Nếu nhìn vào danh mục 31 chỉ báo định lượng và 8 chỉ báo định tính của hợp phần chính sách xã hội trong khung SGI, những người am hiểu có thể thấy các nguồn số liệu thống kê chính thức và tài liệu nghiên cứu có liên quan hiện có đã khá dồi dào cho việc phân tích chính sách xã hội ở Việt Nam dựa trên khung SGI. Điều này cũng tương đối đúng nếu nói đến khả năng dữ liệu cho việc phân tích rộng hơn, đánh giá quản trị bền vững ở Việt Nam theo khung SGI. Trên thực tế, đã có công trình dựa trên khung SGI có sửa đổi để nghiên cứu một mẫu các nước châu Á, trong đó có Việt Nam (Gobel and Maslow). Theo hai tác giả này, Việt Nam có vẻ là một ngoại lệ thú vị trong khuôn khổ phân tích SGI: “Chệch khỏi những khuôn mẫu chung là những ngoại lệ đáng chú ý ở Việt Nam, nơi tuổi thọ kỳ vọng tăng nhanh, bao gồm xã hội và bảo vệ môi trường cũng đạt điểm số cao hơn những nước thu nhập trung bình thấp khác" (Gobel and Maslow: 78) ${ }^{(4)}$.

\section{- Chú thích}

(1) Tỷ lệ NEET [NEET rate]: tỷ lệ phần trăm thanh niên không có việc làm, không nhận được mức giáo dục và đào tạo ("percentage of the young population is not in employment, education or training") (SGI Sustainable Governance Indicators and Bertelsmann Stiftung, 2019a, https://www.sgi-network.org/2019/Policy_Performance/Social_Policies/Social_Inclusion/NEET_Rate).

(2) Tỷ số Palma [Palma ratio]: Phần của $10 \%$ nhóm dân cư giàu nhất trong tổng thu nhập quốc dân [GNI] chia cho phần của $40 \%$ nhóm dân cư nghèo nhất trong tổng thu nhập quốc dân ("the ratio of the richest $10 \%$ of the population's share of gross national income divided by the poorest $40 \%$ 's share") (SGI Sustainable Governance Indicators and Bertelsmann Stiftung, 2019a, https://www.sgi-network.org/2019/Policy_Performance/Social_Policies/Social_Inclusion/Palma_Ratio). 
(3) FB-N viết tắt cho cụm từ "tỷ số của người sinh ở nước ngoài so với người bản địa" ("ration of foreignborn to native") (SGI Sustainable Governance Indicators and Bertelsmann Stiftung, 2019a, https://www.sgi-network.org/2019/Policy_Performance/Social_Policies/Integration).

(4) Nguyên tác: "'Notable expectations to the general patterns are Vietnam, where life expectancy has soared, and which scores are higher than the other low-middle-income economies in the areas of social inclusion and environmental protection" (Gobel and Maslow: 78).

\section{TÀI LIẸU THAM KHẢO}

[1] Ganev, Georgy, Maria Popova, and Frank Bonker (Coordinator). 2019. Bulgaria Report: Sustainable Governance Indicators. SGI Sustainable Governance Indicators and Bertelsmann Stiftung. https://www.sgi-network.org/docs/2019/country/SGI2019_Bulgaria.pdf

[2] Gobel, Christian and Sebastian Maslow. Assessing Pathways to Success: Need to Reform and Governance Capacities in Asia. Deutschland und Asien and SGI Sustainable Governance Indicators. https://www.sgi-network.org/docs/studies/Asia\%20Study_Assessing_Pathways_to_Success.pdf

[3] Kalinowski, Thomas, Sang-young Rhyu, and Aurel Croissant (Coordinator). 2019. South Korea Report: Sustainable Governance Indicators. SGI Sustainable Governance Indicators and Bertelsmann Stiftung. https://www.sgi-network.org/docs/2019/country/SGI2019_South_Korea.pdf

[4] SGI Sustainable Governance Indicators and Bertelsmann Stiftung. 2019a. SGI 2019 Survey. https://www.sgi-network.org/2019/

[5] SGI Sustainable Governance Indicators and Bertelsmann Stiftung. 2019b. Codebook: Sustainable Governance Indicators 2019. https://www.sgi-network.org/docs/2019/basics/SGI2019_Codebook.pdf

[6] Schraad-Tischler, Daniel and Laura Seelkopf. 2015. Concept and Methodology Sustainable Governance Indicators 2015. SGI Sustainable Governance Indicators. https://www.sgi-network.org/docs/2019/basics/SGI_Concept.pdf

[7] Sverdrup, Ulf, Stein Ringen, and Detlef Jahn (Coordinator). 2019. Norway Report: Sustainable Governance Indicators. SGI Sustainable Governance Indicators and Bertelsmann Stiftung. https://www.sgi-network.org/docs/2019/country/SGI2019_Norway.pdf 